\title{
Distribution of coloured dissolved and detrital organic matter in optically complex waters of Chilika lagoon, Odisha, India, using hyperspectral data of AVIRIS-NG
}

\author{
Arvind Sahay ${ }^{1, *}$, Anurag Gupta ${ }^{1}$, Gunjan Motwani ${ }^{1}$, Mini Raman ${ }^{1}$, \\ Syed Moosa Ali ${ }^{1}$, Meghal Shah ${ }^{2}$, Shard Chander ${ }^{1}$, Pradipta R. Muduli ${ }^{3}$ and \\ R. N. Samal ${ }^{3}$ \\ ${ }^{1}$ Marine Ecosystem Division, Biological and Planetary Sciences and Applications Group, Earth, Ocean, Atmosphere, Planetary Sciences and \\ Applications Area, Space Applications Centre, Ahmedabad 380 015, India \\ ${ }^{2}$ Department of Botany, University of Gujarat, Ahmedabad 380009 , India \\ ${ }^{3}$ Wetland Research and Training Centre, Chilika Development Authority, Department of Forest and Environment, Government of Odisha, \\ Balugaon 752 030, India
}

\begin{abstract}
Coloured dissolved and detrital matter (CDM) forms a significant fraction of the total dissolved organic matter (DOM) in water bodies. It absorbs light strongly in the ultraviolet and blue domains of the electromagnetic spectrum. The present study maps CDM absorption of the entire Chilika lagoon, Odisha, India (an optically complex water body) using hyperspectral data of AVIRIS-NG. This study takes advantage of hyperspectral data which use SWIR bands for the estimation of remote sensing reflectance in highly turbid waters of Chilika lagoon (northern sector, which otherwise is masked using standard atmospheric correction schemes). During 24-27 December 2015, we have collected in situ bio-optical data over waters of Chilika lagoon, for studying the distribution of CDM. AVIRIS-NG data have also been acquired synchronous to in situ measurements over the study
\end{abstract}

Keywords: Dissolved organic matter, hyperspectral data, lagoon, optically complex waters.

\section{Introduction}

CHROMOPHORIC (or coloured) dissolved organic matter $(\mathrm{CDOM})$ is a fraction of dissolved organic matter (DOM) that absorbs light in the range of ultraviolet (UV) and visible (VIS) wavelengths, causing yellow or brown colour, and is thus called coloured DOM. It is one of the important inherent optical properties of water, which can be detected from airborne or satellite-based optical sensors having UV/blue spectrum. CDOM is that part of organic carbon which passes through $0.20 \mu \mathrm{m}$ filter. It is an indicator of loadings of organic matter by rivers, adjacent soils,

\footnotetext{
*For correspondence. (e-mail: arvindsahay@sac.isro.gov.in)
}

area. CDM absorption coefficient is retrieved using quasi analytical algorithm and the distribution of CDM is discussed in detail in three different sectors of Chilika lagoon (southern, central, northern) and at the outer channel. The variability of CDM absorption at $412 \mathrm{~nm}$ shows that in the north sector of Chilika lagoon, CDM absorption is quite high compared to other sectors $\left(5.5 \mathrm{~m}^{-1}\right.$ with a standard deviation of $0.06 \mathrm{~m}^{-1}$ ). In the southern sector and at the outer channel it is $1.8 \mathrm{~m}^{-1}$ with a standard deviation of $0.02 \mathrm{~m}^{-1}$ and in the central sector it is $3.76 \mathrm{~m}^{-1}$ with a standard deviation of $0.22 \mathrm{~m}^{-1}$. High CDM in the northern sector is attributed to the inflow of terrestrial organic matter. The advantage of hyperspectral data is that it gives CDM absorption contiguous in the range of $375-425 \mathrm{~nm}$, where the absorption by CDM is strong and away from chlorophyll- $a$ absorption. forests and wetlands. Satellite or aerial imageries are used to study the distribution of light absorption due to coloured dissolved and detrital materials (CDM). Light absorption by CDM tends to be strongest at short wavelengths (UV to blue), while diminishing to near zero in the red wavelength region of the electromagnetic spectrum ${ }^{1}$. So CDM level is often represented by a CDM absorption coefficient (inherent optical property) and is detected using UV/blue region of light by the remote sensing community $^{2-4}$. CDM is considered for remote sensing retrievals, as it is not possible to differentiate CDOM and detritus particulate absorption from remote sensing measurements $^{5}$. However, analysis of extensive field datasets indicates that detrital particulates make only a small contribution to CDM (ref. 1) and it is possible to estimate CDOM separately from field datasets ${ }^{6}$. CDM represents carbon pools stored in oceans, and inland and coastal water bodies. Terrestrial ecosystems are highly productive 
and their contributions to CDM are significant. Rivers contribute significant amount of CDM in the coastal oceans. Particles from terrestrial ecosystems are primarily deposited in the coastal region and CDM is considered the main agent for transporting terrestrial organic carbon into the deep ocean. Coastal wetlands are productive ecosystems. Coastal lagoons are known to be highly unstable environments and occupy $13 \%$ of the world's coastal areas $^{7}$. They are often affected by both natural and anthropogenic influences ${ }^{8,9}$. Industrial wastes, urbanization of catchment areas, domestic sewage and fertilizers run-off from agricultural lands are the plausible causes for the degradation of coastal wetlands. A recent report by Gupta et $a l .{ }^{10}$ describes biodiversity and degradation of coastal wetlands exhaustively. Chilika lagoon, Odisha, India, is a coastal wetland and largest brackish water lagoon in Asia. To study CDM in optically complex waters of Chilika lagoon our objectives are: (i) To analyse in situ reflectance spectra in various sectors of Chilika lagoon for categorizing CDM. (ii) To estimate CDM absorption coefficient from AVIRIS-NG radiance data in Chilika lagoon. (iii) To study the distribution of CDM in different sectors of Chilika lagoon, including the outer channel.

\section{Study area}

Chilika lagoon on the east coast of India $\left(19^{\circ} 28^{\prime}-\right.$ $\left.19^{\circ} 54^{\prime} \mathrm{N} ; 85^{\circ} 06^{\prime}-85^{\circ} 35^{\prime} \mathrm{E}\right)$ is one of the important wetlands in the country and is the largest brackish water lagoon in Asia. It is a good site for studying optically complex waters from a spaceborne platform. Chilika being connected by sea through a mouth in the northern sector and by many tributaries in the northern, central and southern sectors, provides a suitable site to study such optically complex waters. The lagoon, a shallow (mean depth $\sim 1.5 \mathrm{~m} ; 0.9-3.5 \mathrm{~m}$ ) brackish water body, is pearshaped and covers an area of about 1000 sq. km during monsoon (August-October), which is reduced by nearly $60 \%$ during pre-monsoon (April-May) when evaporation far exceeds precipitation ${ }^{10}$. It has a catchment area of approximately $4146 \mathrm{sq} . \mathrm{km}$, with average rainfall of $1238 \mathrm{~mm}$ (in 72 rainy days) through June-September (southwest or summer monsoon) and November-December (winter monsoon). Nearly $75 \%$ of rainfall occurs during SW monsoon with peak intensity during August.

In the northern side of the lagoon, tributaries of the Mahanadi River such as Daya, Nuna and Bhargavi join it and discharge large amounts of freshwater and sediment influx to the lagoon. Several million tonnes of sediments enter the lagoon during one year ${ }^{11}$. Chilika lagoon has been declared as a Ramsar site, a 'Wetland of International Importance'. Due to choking of the outer channel in the northern side, the exchange of water between the lagoon and the sea is severely affected ${ }^{12}$. Several other factors like siltation, large change in salinity; freshwater inputs from the northern sector, and anthropogenic activities also affect the biodiversity of the lake. Studies related to DOM dynamics have been conducted earlier in Chilika $^{13-16}$.

Figure 1 shows the coverage by AVIRIS-NG over Chilika lagoon (a mosaic of 12 scenes of AVIRIS-NG flight) for this study. The station locations for collecting in situ bio-optical data with longitude and latitude are shown as red circles.

\section{Material and methods}

\section{In situ optical data}

In situ measurements of upwelling radiance and downwelling irradiance by Satlantic underwater hyperspectral radiometer have been made (Figure 2) for deriving remote sensing reflectance to study the optical response of light at various locations in Chilika lagoon. We have shown three different bio-optical regimes of Chilika lagoon using in situ optical data collected during the AVIRIS-NG campaign. The outer channel forms the fourth region of the study, where it is connected by a mouth through which marine water comes inside the lagoon and exchanges water with it. Figures 3-5 show in situ bio-optical data collected in three different regions of Chilika lake, namely southern, central and northern sectors. To calculate remote sensing reflectance, first the water-leaving radiance is computed by eq. (1) using upwelling radiance.

$$
L_{\mathrm{w}}\left(0^{+}, \lambda\right)=L_{u}\left(0^{-}, \lambda\right) \frac{1-\rho(\lambda)}{\eta_{\mathrm{w}}^{2}(\lambda)},
$$

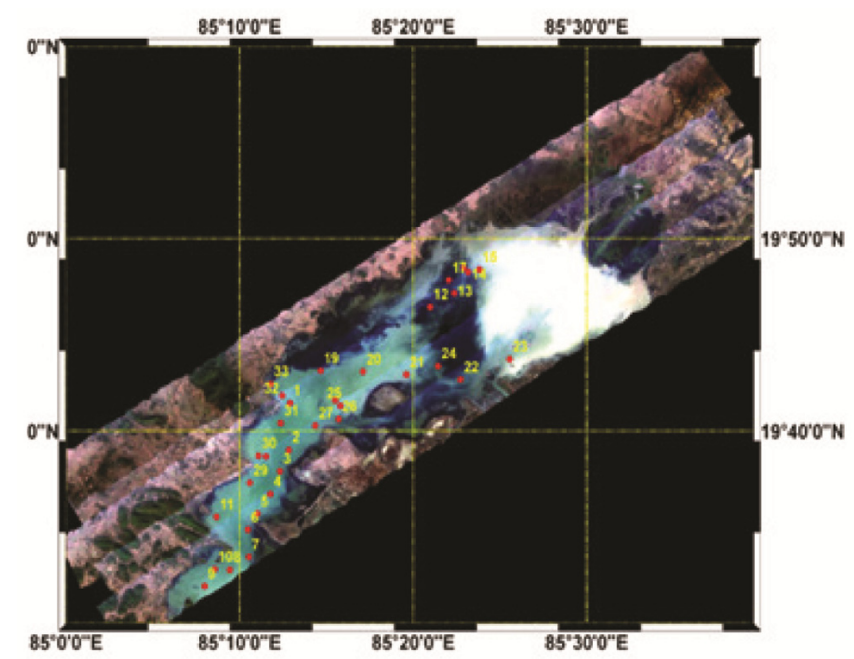

Figure 1. Study area of Chilika lagoon, Odisha, India. The map shows AVIRIS-NG natural colour composite (NCC) image with station locations (red circles) in the field. 
where $L_{\mathrm{w}}\left(0^{+}, \lambda\right)$ is the water-leaving radiance just above the sea surface; $L_{u}\left(0^{-}, \lambda\right)$ the water-leaving radiance just below the sea surface; $\rho(\lambda)$ the Fresnel reflectance index of seawater and $\eta_{\mathrm{w}}(\lambda)$ is the refractive index of seawater.

The computation of normalized water-leaving radiance $L_{\mathrm{wn}}(\lambda)$ and surface remote sensing reflectance from in situ data has been done using the following formulas ${ }^{17}$

$$
L_{\mathrm{wn}}(\lambda)=L_{\mathrm{w}}(\lambda) \frac{F_{\mathrm{o}}(\lambda)}{E_{d}\left(0^{+}, \lambda\right)},
$$

where $F_{\mathrm{o}}(\lambda)$ is the extra-terrestrial solar irradiance. $E_{d}\left(0^{+}, \lambda\right)$ denotes downwelling spectral irradiance measured just above the water surface.

$$
\begin{aligned}
& R_{\mathrm{rs}}(\lambda)=\frac{L_{\mathrm{w}}(\lambda)}{E_{d}\left(\lambda, 0^{+}\right)}, \\
& E_{\mathrm{d}}\left(0^{-}, \lambda\right)=E_{\mathrm{d}}\left(0^{+}, \lambda\right) *(1+\alpha),
\end{aligned}
$$

where $\alpha=0.043$ is the Fresnel reflectance for irradiance from the sun and sky.

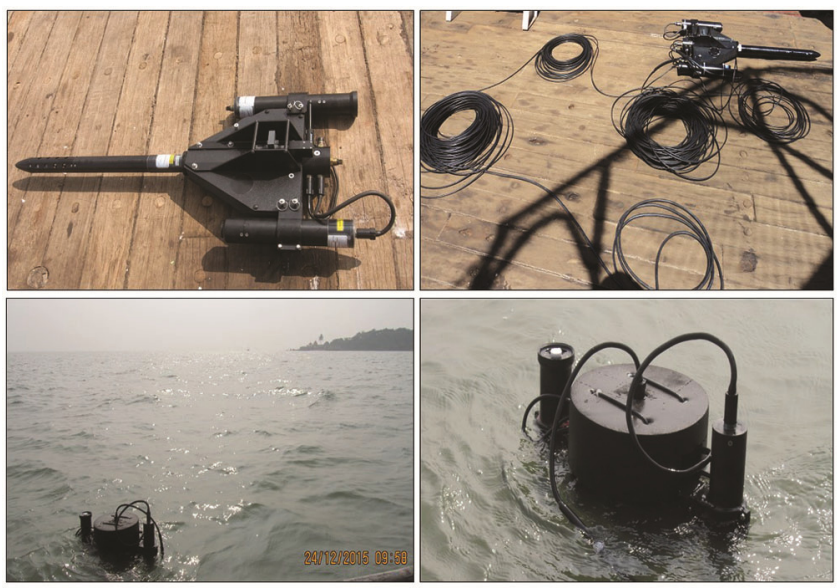

Figure 2. In situ data collection in Chilika lagoon during AVIRISNG campaign (24-27 December 2015).

(a)

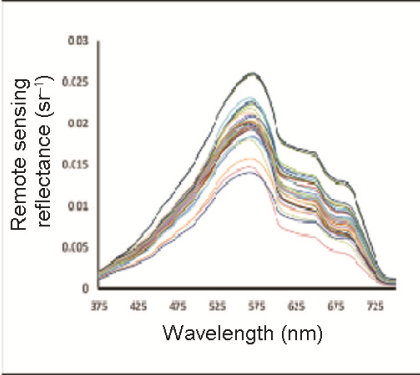

(b)

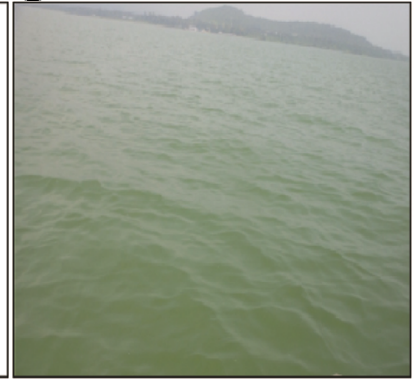

Figure 3. (a) Reflectance profiles and (b) field photograph of the southern sector.
Quasi analytical algorithm for inversion of AVIRIS-NG radiance and retrieval of CDM

During joint campaign of Indian Space Research Organisation and National Aeronautical Space Administration (ISRO/NASA) (24-27 December 2015); AVIRIS-NG data were acquired (site id 54, 100 and 92) over waters of Chilika lagoon. The spatial resolution of the AVIRIS-NG radiance data was $8 \mathrm{~m}$ over this site in the spectral region $380-2510 \mathrm{~nm}$ at an interval of $5 \pm 0.5 \mathrm{~nm}$. We studied CDM absorption in the whole area of Chilika lagoon using AVIRIS-NG radiance data. Since in situ data at the mouth could not be collected due to strong currents, we have used AVIRIS-NG data to describe CDM variability at the mouth (outer channel) where a lot of marine water enters the lagoon and exchanges water with it. CDM absorption coefficient was retrieved using Quasi Analytical Algorithm (QAA) inversion method of Lee et al. ${ }^{18}$ from AVIRIS-NG L-2 data into four sectors of the lagoon.

The semi-analytical model for deriving below-surface remote sensing reflectance $\left(r_{\mathrm{rs}}\right)$ can be described by eq. (5). The parameter $(u)$, which is the ratio of backscattering to total extinction is given by eq. (6). The reference wavelength is important in the QAA inversion method. We have taken band-37 (556.7 nm of AVIRIS-NG) as reference wavelength, as described by Lee et al. ${ }^{18}$. Empirical approach for deriving total absorption at reference wavelength is given by eq. (7) which uses remote sensing reflectance at $441.5 \mathrm{~nm}$ (band-14) and $556.7 \mathrm{~nm}$ (band-37) wavelengths. Once the total absorption at reference wavelength is computed, the total backscattering at
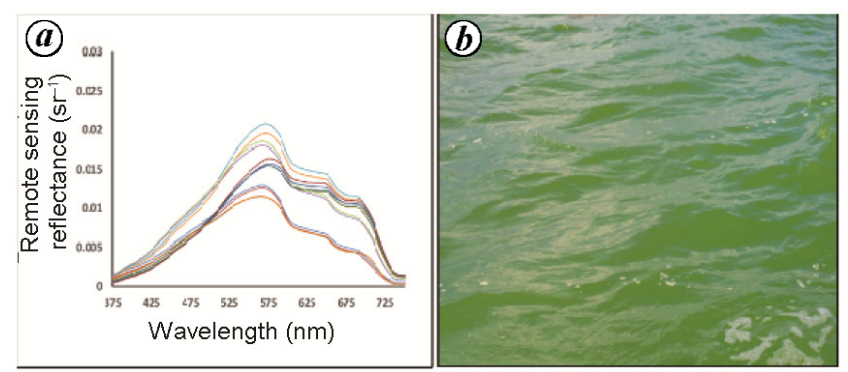

Figure 4. (a) Reflectance profiles and (b) field photograph of the central sector.

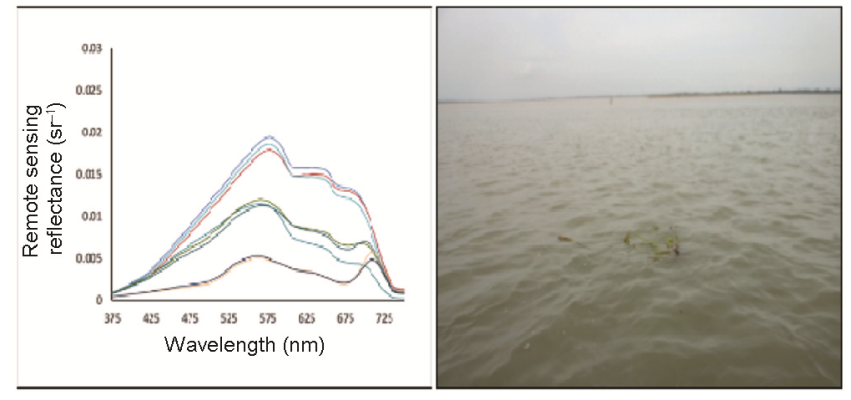

Figure 5. (a) Reflectance profiles and (b) field photograph of the northern sector.

CURRENT SCIENCE, VOL. 116, NO. 7, 10 APRIL 2019 
reference wavelength is given by eq. (8). The power equation and parameter $Y$, which governs the backscattering shape is given by eq. (9). Once the $Y$ parameter is known, then using wavelengths 441.5 and $556.7 \mathrm{~nm}$, total backscattering and total absorption at other wavelengths can be computed using eqs (10) and (11) respectively. $\mathrm{CDM}$ is finally derived using eq. (12) below.

$$
\begin{aligned}
& r_{\mathrm{rs}}=\frac{R_{\mathrm{rs}}}{0.52+1.7 R_{\mathrm{rs}}}, \\
& u(\lambda)=\frac{-g_{0}+\left[\left(g_{0}\right)^{2}+4 g_{1} r_{\mathrm{rs}}(\lambda)\right]^{1 / 2}}{2 g_{1}},
\end{aligned}
$$

with $g_{0}=0.0895$ and $g_{1}=0.1247$.

$$
a(555)=0.0596+0.2[a(443)-0.01],
$$

where $a(443)=\exp \left(-2.0-1.4 \rho+0.2 \rho^{2}\right) \quad$ and $\rho=\ln \left[r_{\mathrm{rs}}\right.$ $\left.(443) / r_{\mathrm{rs}}(555)\right]$.

$$
\begin{gathered}
b_{\mathrm{bp}}(555)=\frac{u(555) a(555)}{1-u(555)}-b_{\mathrm{bw}}(555), \\
Y=2.2\left[1-1.2 \exp \left\{-0.9 \frac{r_{\mathrm{rs}}(443)}{r_{\mathrm{rs}}(555)}\right\}\right], \\
b_{\mathrm{bp}}(\lambda)=\left[b_{\mathrm{bp}}(555)\right][555 / \lambda]^{Y}, \\
a(\lambda)=\frac{b_{\mathrm{bp}}(\lambda)[1-u(\lambda)]}{u(\lambda)}+b_{\mathrm{bw}}(\lambda), \\
a g(440)=\frac{[a(410)-a(440)]}{\tau-\phi}-\frac{[a w(410)-a w(440)]}{\tau-\phi},
\end{gathered}
$$

where $\tau=0.71+0.06 /\left(0.08+r_{\mathrm{rs}}(440) / r_{\mathrm{rs}}(555)\right)$ and $\phi=$ $\exp (S(440-410))$.

\section{Distribution of CDM absorption using in situ and AVIRIS-NG radiance data}

The productivity of Chilika is described in the literature $^{13-15,19,20}$. The northern sector of the lagoon maintains high productivity compared to other sectors as the nutrient stoichiometry is observed to be close to Redfield ratio (despite light limitations due to high suspended particulate matter). The southern sector (SS) of the lagoon maintains lowest primary productivity (PP) even though it is the region with highest transparency. The low PP could be attributed to lowest nutrient content in SS compared to other sectors.
The northern sector of the Chilika waters has highest productivity as well as high turbidity, as discussed above. Many rivers and their tributaries bring a lot of freshwater and nutrients into this region. This makes the northern sector more turbid and productive. The water is turbid brown instead of bright green, compared to the central and southern sectors of the lagoon (Figure $5 b$ ). The reflectance from green to near infrared, i.e. from 550 to $700 \mathrm{~nm}$ does not decrease sharply; rather a flat portion of the spectra is observed in this region of the electromagnetic spectrum (due to suspended sediment backscattering).

Figure 6 represents in situ reflectance spectra in the region of $375-425 \mathrm{~nm}$, where absorption by CDM is strong. The spectra reveal three distinct groups (categories) of CDM absorption at three sectors of Chilika (southern, central and northern). The lowest reflectance represents the highest absorption by CDM and vice versa.

Figure $7 a$ shows a map of CDM absorption coefficient and Figure $7 b$ represents the contiguous spectra (376$600 \mathrm{~nm}$ ) of CDM absorption coefficient at four different locations.

At location-1, which is the southern sector (lat. $19^{\circ} 32^{\prime} 15^{\prime \prime}$ and long. $85^{\circ} 9^{\prime} 52^{\prime \prime}$ ), CDM absorption coefficient is derived within a circular area of 50 sq. m; the mean value of CDM absorption coefficient is $1.86 \mathrm{~m}^{-1}$ with a standard deviation of $0.05 \mathrm{~m}^{-1}$. The southern sector remains comparatively saline $(10.5 \pm 3.5)$ throughout the year, as seawater exchange takes place through a discrete connection (i.e. Palur canal) further south to Rambha Bay. At location-2, which is the central sector (lat. $19^{\circ} 44^{\prime} 8^{\prime \prime}$ and long. $85^{\circ} 19^{\prime} 01^{\prime \prime}$ ), the mean value of absorption coefficient is $3.76 \mathrm{~m}^{-1}$ with a standard deviation of $0.22 \mathrm{~m}^{-1}$ within a circular area of $50 \mathrm{sq} . \mathrm{m}$. This analysis shows that the central part of the Chilika has comparatively higher value than the southern part. At location-3 (northern sector); lat. $19^{\circ} 48^{\prime} 16^{\prime \prime}$ and long. $85^{\circ} 29^{\prime} 8^{\prime \prime}$

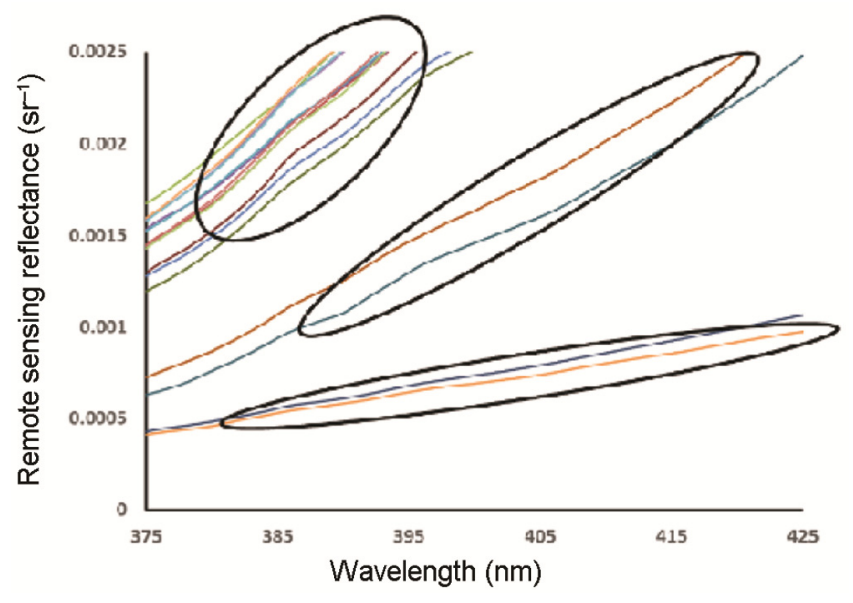

Figure 6. Field reflectance spectra of the three different types of $\mathrm{CDM}$ absoprtion grouped into three classes. 
within a circular area of $50 \mathrm{sq} . \mathrm{m}$, the mean value of $\mathrm{CDM}$ absorption coefficient is $5.50 \mathrm{~m}^{-1}$ with a standard deviation of $0.06 \mathrm{~m}^{-1}$. The northern sector is characterized by high turbidity, poor water transparency, high nutrient levels and low water salinity due to the discharge of four rivers (Makara, Daya, Nuna, Bhargavi) into the system $^{16}$. CDM absorption coefficient in the northern sector shows a high value compared to all other sectors (Figure 4 b). At location-4 (outer channel); lat. 19 $9^{\circ} 9^{\prime} 36^{\prime \prime}$ and long. $85^{\circ} 27^{\prime} 32^{\prime \prime}$, the derived CDM absorption coefficient is $1.90 \mathrm{~m}^{-1}$ with a standard deviation of $0.22 \mathrm{~m}^{-1}$. The entire lagoon experiences seawater exchange predominantly through the outer channel (i.e. Gabakunda).

Our analysis shows that the southern sector and mouth have values of CDM absorption in the range 1.86$1.90 \mathrm{~m}^{-1}$, which is probably due to the high saline water entering the southern area through Palur canal and making the area more saline (like at the outer channel near the mouth) compared to the central and northern sectors. The northern sector shows highest CDM absorption since
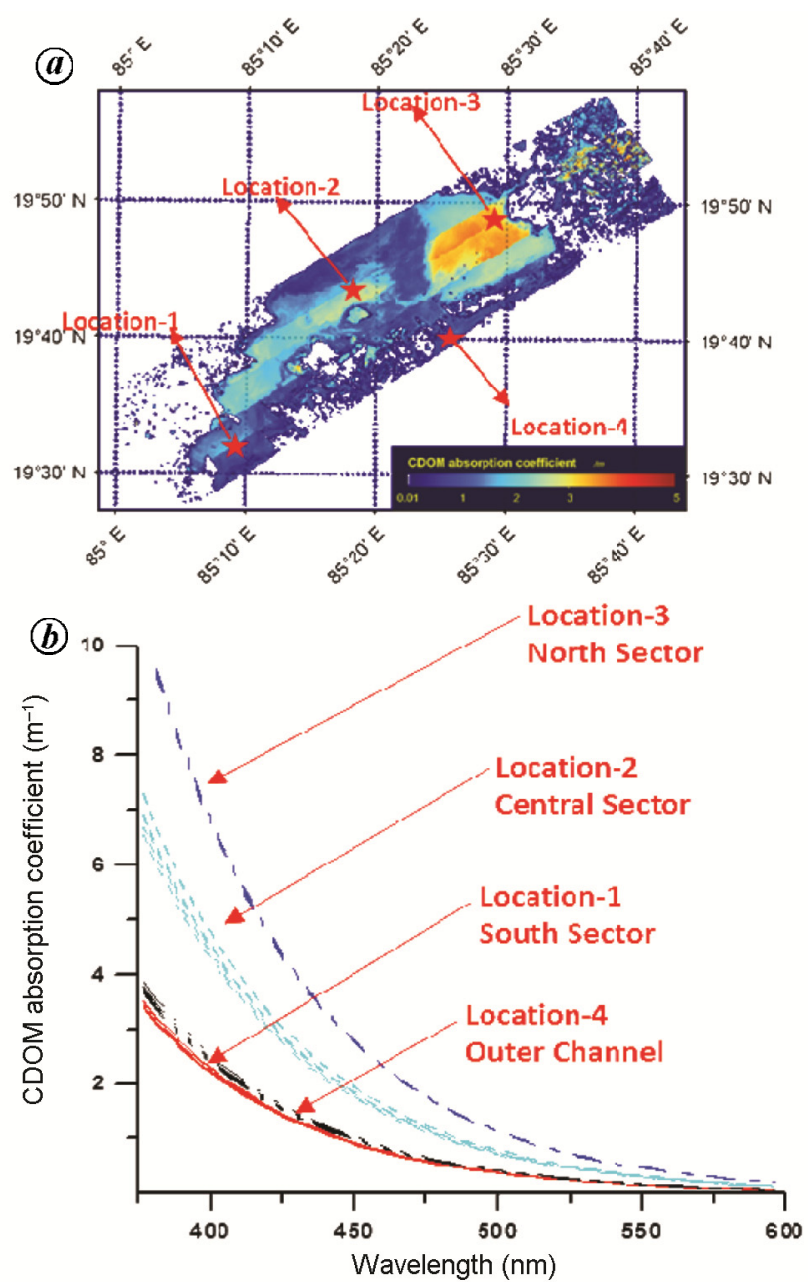

Figure 7. $\boldsymbol{a}$, Map of CDM absorption coefficient using AVIRIS-NG over Chilika lagoon, 27 December 2015. b, Spectra of CDM absorption coefficient. there are rivers which bring a lot of terrestrial dissolved and detrital matter into this area, making it more productive. The advantage of hyperspectral data is that they give CDM absorption contiguous in the range $375-425 \mathrm{~nm}$, where absorption by CDM is strong (Figure 6) and is away from chlorophyll- $a$ absorption.

Similar type of field measurements of coloured dissolved organic matter were done by Keith et $a l^{21}$ (in estuarine and optically complex water environment) in Narragansett Bay, Rhode Island; Neuse River, North Carolina, and St Andrews Bay, Florida, USA. They measured CDOM absorption values at $412 \mathrm{~nm}$ between 0.1 and $7 \mathrm{~m}^{-1}$ that are similar to our retrieved absorption coefficients in different sectors of Chilika. Keith et al. ${ }^{21}$ also used remotely sensing reflectances retrieved from medium resolution imaging spectrometer (MERIS) and the International Space Station (ISS) Hyperspectral Imager for the Coastal Ocean (HICO) images to estimate CDOM absorption in different parts of optically complex water. Similar type of optical properties of chromophoric dissolved organic matter were studied by D'Sa et al. ${ }^{22}$ in the Barataria Bay, USA, influenced by marine waters, to the upper basin influenced by freshwater sources. CDOM absorption at $412 \mathrm{~nm}$ varied between 0.74 and $5.2 \mathrm{~m}^{-1}$ at different locations influenced by freshwater sources, which is similar to our results in the northern region of Chilika lagoon, where the influence of freshwater increases CDM absorption.

\section{Summary and conclusion}

The objectives of this study were to map CDM in optically complex and brackish water environment of Chilika lagoon using AVIRIS-NG. We have studied CDM absorption $(412 \mathrm{~nm})$ in three different sectors of Chilika. It is observed that in the northern sector of Chilika, CDM absorption is quite high, i.e. $5.5 \mathrm{~m}^{-1}$ with a standard deviation of $0.06 \mathrm{~m}^{-1}$, comparable to other sectors of the lagoon. The research finding suggests that the distribution of CDM is higher in the northern sector of Chilika. The plausible cause for this may be the many rivers, tributaries and estuaries in the northern part of Chilika which bring a lot of terrestrial organic matter into the area. The future scope of research is the mapping of CDM slope (with CDM absorption) in different sectors of Chilika. The slope information can be used to describe the composition or origin of CDM, which is important for the biogeochemical processes in the coastal marine environment.

1. Markager, S. and Vincent, W. F., Spectral light attenuation and the absorption of UV and blue light in natural waters. Limnol. Oceanogr., 2000, 45, 642-650.

2. Brando, V. E. and Dekker, A. G., Satellite hyperspectral remote sensing for estimating estuarine and coastal water quality. IEEE Trans. Geosci. Remote Sensing, 2003, 41, 1378-1387. 
3. Menon, H. B., Sangekar, N. P., Lotliker, A. A. and Vethamony, P., Dynamics of chromophoric dissolved organic matter in Mandovi and Zuari estuaries - a study through in situ and satellite data. ISPRS J. Photogramm. Remote Sensing, 2011, 66, 545-552.

4. Watanabe, F., Mishra, D. R., Astuti, I., Rodrigues, T., Alcântara, E., Imai, N. N. and Barbosa, C., Parameterization and calibration of a quasi-analytical algorithm for tropical eutrophic waters. ISPRS J. Photogramm. Remote Sensing, 2016, 121, 28-47.

5. Siegel, D. A., Maritorena, S., Nelson, N. B., Hansell, D. A. and Lorenzi-Kayser, M., Global distribution and dynamics of coloured dissolved and detrital organic materials. J. Geophys. Res., 2002, 107(C12), 3228; doi:10.1029/2001JC000965.

6. Sarma, N. S. et al., Spectral modelling of estuarine coloured dissolved organic matter. Curr. Sci., 2018, 114(8), 1762-1767.

7. Barnes, R. S. K., Coastal lagoons. In Cambridge Studies in Modern Biology 1, Cambridge University Press, New York, 1980, p. 106.

8. Sikora, W. B. and Kjerfve, B., Factors influencing the salinity of lake Pontchartrain, Louisiana a shallow coastal lagoon: analysis of a long term data set. Estuaries, 1985, 8(2A), 170-180.

9. Russi, D. et al., The Economics of Ecosystems and Biodiversity for Water and Wetlands, IEEP, London and Brussels, 2013, p. 78.

10. Gupta, G. V. M. et al., Influence of net ecosystem metabolism in transferring riverine organic carbon to atmospheric $\mathrm{CO}_{2}$ in a tropical coastal lagoon (Chilika Lake, India). Biogeochemistry, 2008; http://dx.doi.org/10.1007/s10533-008-9183-x.

11. Patnaik, S. S., Estimation of sediment flow into the Chilika lake. In Abst. Vol., Workshop on Sustainable Development of Chilika Lake, Bhubaneswar, 12-14 December 1998, pp. 31-32.

12. Chandramohan, P. and Nayak, B. U., A study for the improvement of the Chillka Lake tidal inlet, East Coast of India. J. Coast. Res., 1994, 10, 909-918.

13. Muduli, P. R. et al., Spatio-temporal variation of $\mathrm{CO}_{2}$ emission from Chilika Lake, a tropical coastal lagoon, on the east coast of India. Estuarine Coast. Shelf Sci., 2012, 113, 305-313.

14. Muduli, P. R. et al., Distribution of dissolved inorganic carbon and net ecosystem production in a tropical brackish water lagoon, India. Cont. Shelf Res., 2013, 64, 75-87.

15. Muduli, P. R., Barik, S. K., Mohapatra, D., Samal, R. N. and Rastogi, G., The impact of tropical cyclone 'Phailin' on the hydrology of Chilika Lagoon, India. Int. J. Environ. Sci. Nat. Resour., 2017, 4(2), 555632; http://dx.doi.org/10.19080/IJESNR.2017.0.

16. Barik, S. K. et al., Spatio-temporal variability and the impact of Phailin on water quality of Chilika lagoon. Cont. Shelf Res., 2017, 136, 39-56.
17. Mueller, J. L., Fargion, G. S. and McClain, C. R., Ocean optics protocols for satellite ocean colour sensor validation, National Aeronautics and Space Administration, Goddard Space Flight Center, USA, 2002, Revision 4, vol. IV, NASA/TM-2003.

18. Lee, Z., Carder, K. L. and Arnone, R. A., Deriving inherent optical properties from water colour: a multiband quasi-analytical algorithm for optically deep waters. Appl. Opt., 2002, 41, 57555772.

19. Kanuri, V. V. et al., Plankton metabolic processes and its significance on dissolved organic carbon pool in a tropical brackish water lagoon. Cont. Shelf Res., 2013, 61, 52-61.

20. Kanuri, V. V., Muduli, P. R., Robin, R. S., Patra, S., Gupta, G. V. M. and Rao, G. N., Bioavailable dissolved organic matter and its spatio-temporal variation in a river dominated tropical brackish water Lagoon, India. Marine Pollut. Bull., 2018, 131, 460467.

21. Keith, D. J., Lunetta, R. S. and Schaeffer, B. A., Optical models for remote sensing of coloured dissolved organic matter absorption and salinity in new England, Middle Atlantic and Gulf Coast Estuaries USA. Remote Sensing, 2016, 8(4), 283.

22. D'Sa, E. J., Naik, P. and Swenson, E. M., Optical properties of chromophoric dissolved organic matter along a transect in the Barataria Bay, Louisiana. In OCEANS, IEEE, 2008, pp. 1-4.

ACKNOWLEDGEMENTS. We thank the Department of Space, Government of India for financial support to AVIRIS-NG, a joint ISRO-NASA programme with budget code (0303510FA501). We also thank the Director, Space Applications Centre (SAC; ISRO), Ahmedabad and Deputy Director EPSA/SAC for support and guidance during the programme. We also express our sincere thanks to Dr Prakash Chauhan, Group Director BPSG/EPSA/SAC; all members of the flight team, who coordinated with the ground team; especially the efforts made by team SEDA/SAC during the campaign phase; Dr Ajit Pattnaik, Dr Gurdip Rastogi, and other research staff of the Wetland Research and Training Centre, Chilika Development Authority (CDA), Government of Odisha, for help during in situ data collection. Thank are also due to all those, who are associated directly or indirectly to this AVIRISNG campaign.

doi: $10.18520 / \mathrm{cs} / \mathrm{v} 116 / \mathrm{i} 7 / 1166-1171$ 